\title{
Quantitative study of infarcted myocardium in cardiogenic shock
}

\author{
C. Harnarayan, M. A. Bennett, B. L. Pentecost ${ }^{1}$, and D. B. Brewer \\ From the Department of Pathology, Birmingham University, and the Coronary Care Unit, \\ General Hospital, Birmingham 4
}

\begin{abstract}
A post-mortem study of the heart was performed in 20 patients dying of cardiogenic shock. The extent of infarcted myocardium was defined by using a mitochondrial dehydrogenase stain nitro$B T$ which allowed macroscopical recognition of tissue death as early as I 2 hours. Extensive myocardial injury was found to accompany cardiogenic shock predominantly affecting the left ventricle and the interventricular septum. Severe atheromatous involvement of the coronary arteries was noted.
\end{abstract}

Shock and left ventricular failure remain the major causes of death among patients admitted to hospital with acute myocardial infarction (Lown et al., 1967; Lawrie et al., 1967; Pentecost and Mayne, 1968; Thomas, Jewitt, and Shillingford, I968). In contrast to the improvements in the management of arrhythmias, no therapy has been found to be consistently effective in shock, and the mortality from this complication remains extremely high (Killip and Kimball, 1967; Kuhn, 1967). The question arises whether shock is simply an expression of massive myocardial destruction or, alternatively, whether it is dependent upon some reflex or endocrine mechanism in the presence of only moderate tissue damage (Agress and Binder, 1957).

It is perhaps surprising that there is relatively little evidence concerning the correlation between the clinical state and the extent and distribution of myocardial damage at necropsy. The major difficulty confronting such a study is that shocked patients frequently die before the macroscopical appearance of infarction is fully developed, thus rendering quantitative study impossible. It has, however, been shown that the dehydrogenase systems of the myocardial mitochondria lose their histochemical staining characteristics within 6 to 12 hours of tissue death (Nachlas and Shnitka, 1963; Morales and Fine, 1966; Brody et al., 1967). Histochemical staining thus provides a method of studying

Received 19 March 1970.

1 Requests for reprints should be sent to Dr. B. L. Pentecost, The General Hospital, Birmingham 4. myocardial damage among patients who die more than 12 hours after infarction but before the usual macroscopical evidence of tissue death has fully developed at about 24 to 48 hours. In this study we have used such a technique to examine the hearts of 20 patients who died in cardiac shock after acute infarction.

\section{Material and methods}

Clinical criteria The criteria for the diagnosis of shock were strict (Binder et al., 1955). All patients were hypotensive with a systolic pressure of $80 \mathrm{~mm} . \mathrm{Hg}$ or less as determined by sphygmo-

TABLE I Total ventricular mass infarcted

\begin{tabular}{|c|c|c|c|c|c|}
\hline $\begin{array}{l}\text { Case } \\
\text { No. }\end{array}$ & $\begin{array}{l}\text { Age } \\
(y r .)\end{array}$ & Sex & $\begin{array}{l}W t . \text { of ventricles } \\
(\mathrm{g} .)\end{array}$ & $\begin{array}{l}\text { Wt. of ventricles } \\
\text { infarcted }(\mathrm{g} .)\end{array}$ & $\begin{array}{l}\% \text { of ventricles } \\
\text { infarcted }\end{array}$ \\
\hline I & 69 & $\mathrm{~F}$ & $226 \cdot 7$ & 45.5 & $20 \cdot 0$ \\
\hline 2 & 55 & M & 383.5 & 116.5 & $30 \cdot 2$ \\
\hline 3 & $8 I$ & M & $29 \mathrm{I} \cdot \mathrm{I}$ & $89 \cdot 7$ & $30 \cdot 8$ \\
\hline 4 & 61 & $\mathbf{M}$ & $264 \cdot 2$ & $93 \cdot 2$ & $35 \cdot 2$ \\
\hline 5 & 68 & $\mathbf{M}$ & $276 \cdot 1$ & 98.9 & $35 \cdot 8$ \\
\hline 6 & 65 & $\mathbf{M}$ & 374.4 & $137^{\circ} 0$ & 36.5 \\
\hline 7 & 73 & $\mathbf{F}$ & 174.8 & 69.4 & $39 \cdot 7$ \\
\hline 8 & 54 & $\mathbf{M}$ & $305 \cdot 0$ & 124.9 & 40.9 \\
\hline 9 & 69 & $\mathbf{M}$ & 242.4 & $99 \cdot 6$ & $4 I \cdot I$ \\
\hline 10 & 64 & $\mathbf{M}$ & $316 \cdot 3$ & 136.6 & $43 \cdot I$ \\
\hline II & 73 & F & $202 \cdot 4$ & $87 \cdot 7$ & 43.3 \\
\hline 12 & 59 & $\mathbf{M}$ & 230.9 & $103 \cdot 1$ & $44 \cdot 6$ \\
\hline 13 & 60 & $\mathbf{M}$ & $202 \cdot 6$ & $90 \cdot 7$ & $44 \cdot 7$ \\
\hline 14 & 72 & $\mathbf{M}$ & $212 \cdot 3$ & $97 \cdot 7$ & $46 \cdot 0$ \\
\hline 15 & 76 & $\mathbf{F}$ & 232.9 & 112.8 & $48 \cdot 4$ \\
\hline 16 & 46 & $\mathbf{M}$ & 335.5 & 1647 & $49 \cdot I$ \\
\hline 17 & 58 & $\mathbf{M}$ & $252 \cdot 4$ & 124.5 & $49 \cdot 3$ \\
\hline 18 & 46 & $M$ & 280.5 & 156.3 & $55 \cdot 7$ \\
\hline 19 & $6 I$ & $\mathbf{M}$ & 215.9 & $146 \cdot I$ & $71 \cdot 9$ \\
\hline 20 & 59 & $\mathbf{M}$ & 314.9 & 139.7 & $72 \cdot 0$ \\
\hline
\end{tabular}


manometry and frequently confirmed by direct intravascular measurement. In addition, there was clinical evidence of poor peripheral perfusion as shown by pallor, cold extremities, and usually sweating. The clinical picture was completed by the presence of oliguria and a metabolic acidaemia, in the absence of diabetic ketoacidosis or chronic renal failure. Invariably the initial $p H$ was $<7 \cdot 13$ with a base deficit $>4 \mathrm{mEq} /$ litre. Shock was not diagnosed if the clinical picture was improved by analgesia or oxygen administration, or if the condition was secondary to an underlying arrhythmia such as complete heart block or ventricular tachycardia. There were 16 men and 4 women among the 20 patients. Their ages ranged from 46 to 81 years (mean 63.5). All 20 patients had developed the clinical picture without previous cardiac arrest, i.e. there were no examples of the postresuscitation shock syndrome. The duration of shock before death was variable and lasted between 30 minutes and 16 hours. In all patients the initial episode of infarction occurred at least I2 hours before death.

Pathological technique The bodies were refrigerated at $4^{\circ} \mathrm{C}$. until necropsy, which was always performed within 24 hours of death. Eighty per cent of necropsies were undertaken within I5 hours. Immediately after removal from the body the hearts were frozen in a deep freeze to aid slicing. They were then cut transversely into sections of equal thickness approximately 0.5 to 0.8 $\mathrm{cm}$. in depth, from apex to base including the atria. Each slice was then quickly weighed while still frozen. Sections were briefly rinsed in cold water or saline and incubated for 15 to 20 minutes in a solution of nitro-BT ( $50 \mathrm{mg} . / 100 \mathrm{ml}$.) and in Sorensen's phosphate buffer $(p \mathrm{H} 7.4,0.1 \mathrm{M})$, at $3^{\circ} \mathrm{C}$. according to the method of Nachlas and Shnitka (Nachlas and Shnitka, 1963; Morales and Fine, 1966; Brody et al., 1967). After incubation the stained sections were fixed in ro per cent formalin for 12 to 24 hours and then reweighed. Normal myocardium had a uniform blue stain, infarcted myocardium failed to take up the stain, and old areas of fibrosis appeared as pearly white patches.

A quantitative assessment of the myocardium damage was made by a point counting method (Dunnill, I962; Hicken, Brewer, and Heath, I966). Each slice of myocardium was covered in turn with a transparent sheet of cellulose film in which a regular pattern of small holes had been punched, each $0.2 \mathrm{~cm}$. apart arranged in a series of equilateral triangles. The number of points over the myocardial slice was counted and the tissue under each point classified as stained or unstained, i.e. normal or infarcted. The proportion of infarcted to non-infarcted tissue could then be calculated. This was done for the total ventricular muscle mass, the left ventricle, the septum, and the right ventricle. The coronary arteries were left in situ and were also sliced. They were examined naked-eye, and a search made for arterial occlusion.
TABLE 2 Left ventricular mass infarcted

\begin{tabular}{|c|c|c|c|}
\hline Case No. & $\begin{array}{l}\text { Wt. of left ventricle } \\
(g .)\end{array}$ & $\begin{array}{l}\text { Wt. of left ventricle } \\
\text { infarcted }(g .)\end{array}$ & $\begin{array}{l}\% \text { of left ventricle } \\
\text { infarcted }\end{array}$ \\
\hline I & 142.5 & $35 \cdot 6$ & $24 \cdot 9$ \\
\hline 2 & $221 \cdot 5$ & I 12.9 & $50 \cdot 8$ \\
\hline 3 & $158 \cdot 0$ & $54 \cdot I$ & $34 \cdot 2$ \\
\hline 4 & $141 \cdot 8$ & $68 \cdot 7$ & $48 \cdot 4$ \\
\hline 5 & 136.6 & $53 \cdot 8$ & $39 \cdot 3$ \\
\hline 6 & $208 \cdot 5$ & $73 \cdot 8$ & $35 \cdot 3$ \\
\hline $\begin{array}{l}7 \\
8\end{array}$ & $\begin{array}{r}95.2 \\
158.8\end{array}$ & $\begin{array}{l}45 \cdot 5 \\
85 \cdot 1\end{array}$ & $\begin{array}{l}47 \cdot 7 \\
53 \cdot 6\end{array}$ \\
\hline 9 & $127 \cdot 2$ & 62.9 & $49 \cdot 4$ \\
\hline Io & 194.9 & 85.6 & 43.9 \\
\hline I I & $120 \cdot 3$ & $48 \cdot 6$ & $40 \cdot 3$ \\
\hline 12 & 123.5 & $67 \cdot 7$ & 54.8 \\
\hline 13 & $108 \cdot 6$ & $29 \cdot I$ & $26 \cdot 7$ \\
\hline 14 & II $6 \cdot 0$ & $45 \cdot 4$ & $39 \cdot I$ \\
\hline 15 & 132.9 & $48 \cdot I$ & $36 \cdot 1$ \\
\hline 16 & I 59.7 & $76 \cdot 6$ & $47 \cdot 9$ \\
\hline 17 & 135.3 & 87.9 & 65.7 \\
\hline 18 & 174.0 & II 7.9 & $67 \cdot 7$ \\
\hline 19 & II6.I & $61 \cdot 2$ & $52 \cdot 7$ \\
\hline 20 & 193.9 & 139.7 & $72 \cdot 0$ \\
\hline
\end{tabular}

TABLE 3 Septal mass infarcted

\begin{tabular}{|c|c|c|c|}
\hline Case No. & $\begin{array}{l}\text { Wt. of septum } \\
(g .)\end{array}$ & $\begin{array}{l}W t . \text { of septum } \\
\text { infarcted }(g .)\end{array}$ & $\begin{array}{l}\% \text { of septum } \\
\text { infarcted }\end{array}$ \\
\hline $\mathbf{I}$ & 44.5 & $9 \cdot 9$ & $22 \cdot 2$ \\
\hline 2 & $84 \cdot 6$ & $3 \cdot 6$ & $4 \cdot 2$ \\
\hline 3 & $6 I \cdot 3$ & $32 \cdot 9$ & 53.6 \\
\hline 4 & $49 \cdot 6$ & $24 \cdot 5$ & $49 \cdot 3$ \\
\hline 5 & 75.0 & $28 \cdot 0$ & $37 \cdot 3$ \\
\hline 6 & $93 \cdot 7$ & 52.5 & 56.0 \\
\hline 7 & $42 \cdot 7$ & $23 \cdot 3$ & 54.5 \\
\hline 8 & $76 \cdot 0$ & $25 \cdot 2$ & I9. I \\
\hline 9 & $54 \cdot 2$ & $36 \cdot 6$ & $49 \cdot \mathrm{I}$ \\
\hline I0 & $7 I \cdot 9$ & $32 \cdot 7$ & $45 \cdot 4$ \\
\hline I I & $37 \cdot 0$ & $16 \cdot 3$ & $44 \cdot 0$ \\
\hline I2 & $45 \cdot 7$ & $33 \cdot 3$ & $72 \cdot 8$ \\
\hline 13 & $45 \cdot 6$ & 17.9 & $39 \cdot 7$ \\
\hline 14 & $50 \cdot 1$ & $42 \cdot 2$ & 84.4 \\
\hline 15 & 50.7 & $25 \cdot 3$ & $49 \cdot 9$ \\
\hline 16 & $62 \cdot 2$ & 39.9 & $64 \cdot I$ \\
\hline 17 & $50 \cdot 2$ & $28 \cdot 5$ & 56.9 \\
\hline 18 & $49 \cdot I$ & $29 \cdot 9$ & $60 \cdot 8$ \\
\hline 19 & $40 \cdot 6$ & $40 \cdot 3$ & $99 \cdot 2$ \\
\hline 20 & 65.4 & 34.9 & $53 \cdot 3$ \\
\hline
\end{tabular}

\section{Results}

The extent of total ventricular infarction varied from 20 to 72 per cent (mean $43 \%$ ); it exceeded 30 per cent of the total ventricular muscle mass in all but one patient (Table $\mathrm{r}$ ). The greatest damage involved the left ventricle and the interventricular septum. The quantity of infarcted tissue of the left ventricle ranged from 25 to 72 per cent (mean $46 \%$ ) (Table 2). Interventricular septal infarction varied from 4.2 to 99 per cent (mean 
$51 \%$ ) (Table 3). When the free wall of the left ventricle and the septum were considered together as one structural unit, the extent of myocardial infarction ranged from 24 to 66 per cent (mean $47.3 \%$ ). The right ventricle was involved to a lesser extent except for three hearts that showed extensive infarction (Table 4). Representative examples of ventricular infarction seen in the study are shown in Fig. I-3.

Infarction was found to be transmural in I9 hearts involving the free wall of the left ventricle and the interventricular septum. The deep bulbo-spiral muscle therefore formed the greater part of the infarct. In the heart with only 20 per cent of the ventricular myocardium infarcted the superficial bulboand sino-spiral muscles were involved both subendocardially and subepicardially.

Areas of extensive fibrosis suggesting previous infarction were shown in 8 hearts.

While the study was primarily of the myocardium, macroscopical vascular changes were noted. An occluding thrombus was found in at least one coronary artery in 19 of the 20 hearts examined. The occlusion usually occurred in a vessel showing severe atheromatous disease, by which we mean that there were plaques (with or without calcification) extending along 75 per cent of the major vessel's length, with severe narrowing at more than three points. The occlusion was found in the anterior descending branch of the left coronary artery in 7 hearts, approximately $0.5-1.5 \mathrm{~cm}$. from its origin, in the main circumflex branch of the left coronary artery in 5 cases, and in the right coronary artery, approximately $2.0-2.5 \mathrm{~cm}$. from its origin, in 7. Branch vessels of the main arteries, though occasionally showing atheroma, were never occluded by thrombi. There was severe atheromatous involvement of two main vessels and moderate disease in the third in 12 hearts, and in 7 there was severe disease of two arteries and only slight involvement in the third.

\section{Discussion}

By using a histochemical technique we have shown that the clinical picture of shock complicating myocardial infarction is accompanied by extensive myocardial injury, predominantly affecting the left ventricle and the interventricular septum. The degree of damage to the myocardial muscle bundles makes it tempting to believe that the clinical picture is entirely related to pump destruction and that this degree of myocardial injury may represent an irreversible and untreatable condition. Though this may be the case, there are
TABLE 4 Right ventricular mass infarcted

\begin{tabular}{|c|c|c|c|}
\hline Case No. & $\begin{array}{l}\text { Wt. of right } \\
\text { ventricle }(g .)\end{array}$ & $\begin{array}{l}\text { Wt. of right ven- } \\
\text { tricle infarcted }(g .)\end{array}$ & $\begin{array}{l}\% \text { of right ventricle } \\
\text { infarcted }\end{array}$ \\
\hline I & $40 \cdot 0$ & 0.0 & 0.0 \\
\hline 2 & 79.4 & 0.0 & 0.0 \\
\hline 3 & $71 \cdot 8$ & $2 \cdot 7$ & $3 \cdot 7$ \\
\hline 4 & $72 \cdot 8$ & 0.0 & 0.0 \\
\hline 5 & $64 \cdot 5$ & I7.I & 26.5 \\
\hline 6 & $72 \cdot 2$ & $10 \cdot 7$ & 14.8 \\
\hline 7 & $36 \cdot 9$ & 0.6 & I.6 \\
\hline 8 & $70 \cdot 2$ & 29.5 & $20 \cdot 7$ \\
\hline 9 & $6 r \cdot 0$ & IO.I & 16.5 \\
\hline IO & $49 \cdot 5$ & $18 \cdot 3$ & 36.9 \\
\hline II & $45 \cdot I$ & $22 \cdot 8$ & 50.5 \\
\hline 12 & $6 \mathrm{I} \cdot 7$ & $2 \cdot I$ & $3 \cdot 4$ \\
\hline I3 & $49 \cdot 0$ & $43 \cdot 7$ & $89 \cdot \mathrm{I}$ \\
\hline 14 & $46 \cdot 2$ & IO.I & $2 \mathrm{I} \cdot 8$ \\
\hline $\begin{array}{l}15 \\
16\end{array}$ & $\begin{array}{r}49.3 \\
113.6\end{array}$ & $\begin{array}{l}39 \cdot 4 \\
48 \cdot 2\end{array}$ & $\begin{array}{l}79 \cdot 9 \\
42.4\end{array}$ \\
\hline I7 & $66 \cdot 9$ & 8.1 & $\begin{array}{l}42 \cdot 4 \\
12 \cdot 2\end{array}$ \\
\hline I8 & $57 \cdot 4$ & $8 \cdot 5$ & 14.8 \\
\hline 19 & $49 \cdot 2$ & $44 \cdot 6$ & 90.6 \\
\hline 20 & $55 \cdot 6$ & $16 \cdot 2$ & $29 \cdot 0$ \\
\hline
\end{tabular}

FIG. I Serial sections of a heart in which there were occlusion of the left circumflex artery and severe atheromatous disease of the anterior descending artery. The infarcted tissue appears lighter than non-infarcted myocardium. Transmural infarction is most extensive at the apex where the apical part of the superficial bulbo-spiral muscle is seen to be involved. Towards the region of the atrioventricular ring, infarction involves mainly the lateral wall of the left ventricle.

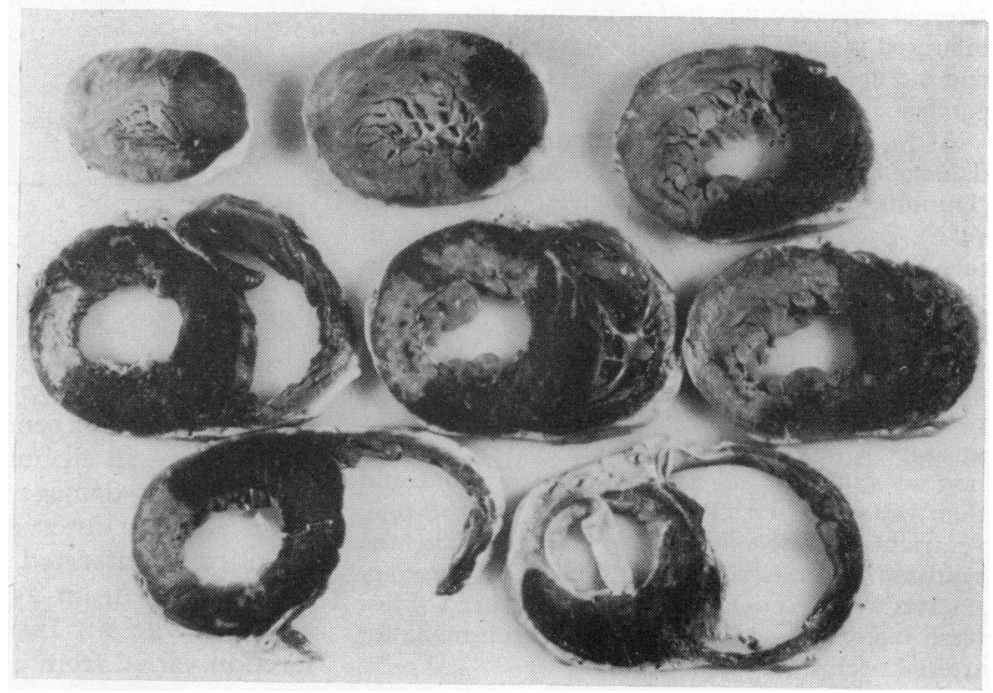


several possible flaws in this concept. First, it would be necessary to show a lesser degree of myocardial injury in those who die from a primary arrhythmia. Many of the patients who die within a few minutes of infarction perhaps belong to this arrhythmic group; a comparison, however, cannot be made with the present series because their early death does not allow time for the area of infarcted myocardium to be clearly defined by any existing technique. Patients who survive 12 or more hours after infarction and then die of primary ventricular fibrillation are rare in a coronary care unit, but we have encountered 2 patients who died after two weeks unexpectedly, presumably from an arrhythmia. In both patients the volume of total ventricular myocardium infarcted was 15 per cent or less. It is true that in the two weeks after infarction some shrinkage of the infarcted area must have occurred.

We have also examined the hearts of 5 patients dying in intractable left ventricular failure between two and three weeks after the initial infarction, and found that the myocardial damage both in extent and distribution was similar to that described among the shocked patients, i.e. the total ventricular myocardium infarcted varying between 32 and 58 per cent. The similarity between the degree of myocardial damage among patients dying in shock and left ventricular failure lends some substance to the argument that shock is simply a manifestation of massive myocardial destruction. On the other hand; it is important to realize that our patients survived for a variable period, during which time their blood pressure either remained low or, having been increased by some pharmacological means, subsequently fell again to hypotensive levels. Persistence of shock has been shown to lead to the development of multiple occlusions throughout the coronary arterial circulation, with presumably extension of the infarction (Blumgart, Schlesinger, and Zoll, 194I). The extent of myocardial injury found at necropsy may therefore reflect a summation of the initial infarction and the secondary effects of hypotension.

Previous conventional necropsy studies have shown no significant difference between the size of infarction among patients dying in shock and those dying suddenly and presumably in ventricular arrhythmia (Rosenberg and Malach, 1960).

Attention has been drawn to the relatively high incidence of branch arterial occlusion, as opposed to main-stem occlusion among patients dying in shock, and it was suggested that a reflex mechanism might be implicated

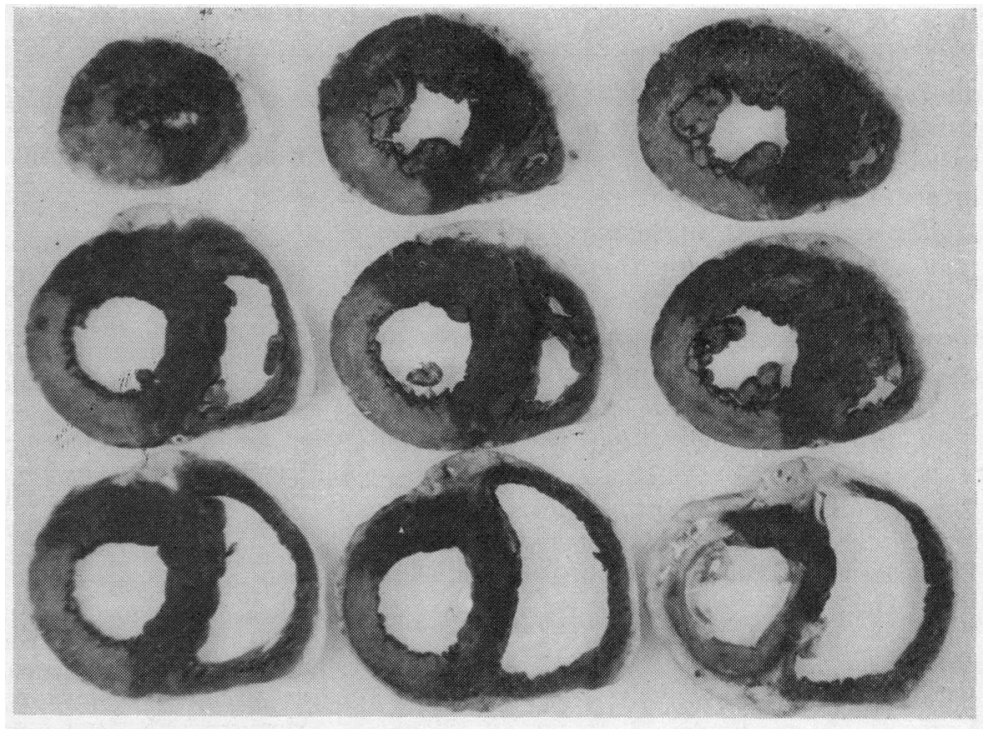

FIG. 2 The left circumflex artery was occluded. Infarction is transmural from apex to base, and involves both superficial and deep muscle bundles - 45 per cent of the left ventricular myocardium was infarcted.

FIG. 3 Occlusion of a dominant right coronary artery has produced extensive infarction of the posterior aspects of both ventricles and septum. The extent of infarction here was 40 per cent in the left ventricle, 44 per cent in the septum, and 50 per cent in the right ventricle.

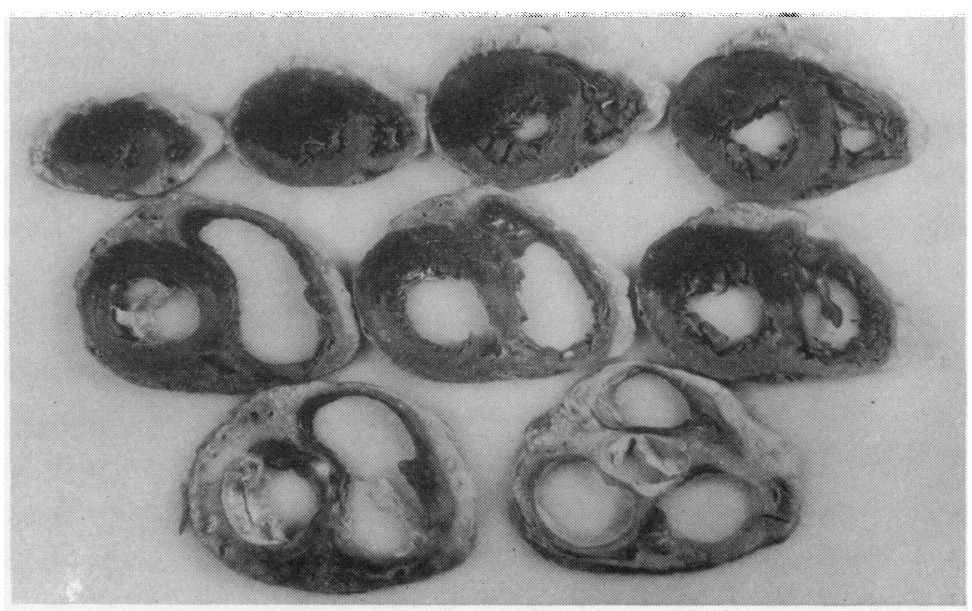


in some patients (Kurland, Weingarten, and Pitt, 1965). Detailed post-mortem coronary angiography was not carried out in the present study, but in I9 out of 20 patients there was at least one occlusion in a main-stem coronary artery.

The prognostic implications of this study may be less pessimistic than at first sight. It remains to be seen whether improved techniques of myocardial support, possibly mechanical, are capable of preventing extension of the infarct or perhaps even of reversing the degree of myocardial damage shown here.

We are indebted to the British Heart Foundation for a grant to Dr. C. Harnarayan. Dr. M. A. Bennet was in receipt of a grant from the Ministry of Health and Social Security.

\section{References}

Agress, C. M., and Binder, M. J. (1957). Cardiogenic shock. American Heart fournal, 54, 458.

Binder, M. J., Ryan, J. A., Jr., Marcus, S., Mugler, F. Strange, D., and Agress, C. M. (1955). Evaluation of therapy in shock following acute myocardial infarction. American fournal of Medicine, 18, 622.

Blumgart, H. L., Schlesinger, M. J., and Zoll, P. M. (194I). Angina pectoris, coronary failure and acute myocardial infarction; the role of coronary occlusions and collateral circulation. Fournal of the American Medical Association, 116, 91.

Brody, G. L., Belding, W. A., Belding, R. M., and Feldman, S. A. (1967). The identification and delineation of myocardial infarcts. Archives of Pathology, 84, 312.

Dunnill, M. S. (1962). Quantitative methods in the study of pulmonary pathology. Thorax, 17, 320.
Hicken, P., Brewer, D., and Heath, D. (1966). The relation between the weight of the right ventricle of the heart and the internal surface area and number of alveoli in the human lung in emphysema. fournal of Pathology and Bacteriology, 92, 529.

Killip, T., and Kimball, J. T. (1967). Treatment of myocardial infarction in a coronary care unit. A two year experience with 250 patients. American fournal of Cardiology, 20, 457.

Kuhn, L. A. (1967). Changing treatment of shock following acute myocardial infarction - a critical evaluation. American fournal of Cardiology, 20, 757.

Kurland, G. S., Weingarten, C., and Pitt, B. (1965). The relation between the location of coronary occlusions and the occurrence of shock in acute myocardial infarction. Circulation, 31, 646.

Lawrie, D. M., Greenwood, T. W., Goddard, M., Harvey, A. C., Donald, K. W., Julian, D. G., and Oliver, M. R. (1967). A coronary-care unit in the routine management of acute myocardial infarction. Lancet, 2, 109.

Lown, B., Fakhro, A. M., Hood, W. B., and Thorn, G. W. (1967). The coronary care unit. New perspective and directions. Fournal of the American Medical Association, 199, 188.

Morales, A. R., and Fine, G. (1966). Early human myocardial infarction. Archives of Pathology, 82, 9.

Nachlas, M. M., and Shnitka, T. K. (I963). Macroscopic identification of early myocardial infarcts by alterations in dehydrogenase activity. American Fournal of Pathology, 42, 379.

Pentecost, B. L., and Mayne, N. M. C. (I968). Results of a general hospital coronary care service. British Medical fournal, $1,830$.

Rosenberg, B. A., and Malach, M. (1960). Acute myocardial infarction in a city hospital. IV. Clinicalpathologic correlations. American fournal of Cardi$\operatorname{olog} y, 6,272$.

Thomas, M., Jewitt, D. E., and Shillingford, J. P. (1968). Analysis of 150 patients with acute myocardial] infarction admitted \{to an intensive ?care and study unit. British Medical fournal, $\mathbf{1}, 787$. 